\title{
Gugulipid, an Extract of Ayurveda Medicine Plant Commiphora Mukul as a Potent Agent for Cancer Chemoprevention and Cancer Chemotherapy
}

\section{Michelle Xiao and Dong Xiao*}

Department of Urology, University of Pittsburgh Cancer Institute, University of Pittsburgh School of Medicine, University of Pittsburgh, Pittsburgh, Pennsylvania 15232, USA

\begin{abstract}
Gugulipid (GL), an extract of Commiphora mukul, has been safely used for thousands of years in the Indian Ayurveda medicine practice for the treatment of different ailments and has been used recently in many clinical trials that focused on its cholesterol-lowering effect. GL has recently been paid great attention for its cancer chemopreventive and chemotherapeutic potential. Z- and E-Guggulsterone have been identified as the major active components of GL. Studies have shown that GL as well as Guggulsterones can inhibit cancer growth in vitro and in vivo and lead to prevention of cancer initiation, promotion and progression. Although the action mechanisms of GL are not completely understood, GL has been revealed as a multitargeted cancer chemopreventive and chemotherapeutic agent. The increased understanding of the anti-cancer activity of $\mathrm{GL}$ and its molecular targets would allow us to improve its efficacies in different types of human cancers by single and/or combination strategies.
\end{abstract}

Keywords: Gugulipid; Guggulsterone; Cancer chemoprevention; Guggul plants

Gugulipid (GL, guggul, guggal, or gugul lipid) is the ethyl acetate extract of gum guggul resin (raw material) that is harvested directly from the Commiphora mukul tree (family name: Burseraceae; synonyms: Hook, Bandari, Balsamodendron mukul, and Commiphora Wightii). GL is a highly valued botanical medicine. As aforementioned, GL has been safely used for thousands of years in the Indian Ayurvedic medicine for the treatment of different ailments, including lipid disorders, rheumatoid arthritis, ulcers, osteoarthritis, bone fractures, epilepsy and obesity [1-5]. In 1986, GL was granted approval in India for marketing as a lipid lowering drug (Indian Pharmacopeia 2007: pgs. 2038-2040). Several products of standardized formulations of Commiphora mukul are already in human use as cholesterollowering agents [1-4]. The Z- and E-forms of guggulsterone (Gug, 4,17(20)-pregnadie-3, 16-dione) have been identified as major active components of GL [1-4]. GL and its active component $z$-Gug have been used in many clinical trials that focused on its cholesterol-lowering effect [1-7]. Numerous studies continue to support that many edible phytochemicals have cancer chemopreventive and chemotherapeutic potential $[8,9]$. These finding motivated the investigation of the cancer chemopreventive and chemotherapeutic potential of GL and its active components.

The evidences of the anti-cancer activity of Gugs were provided by us and other laboratories [10-21]. We, for the first time, investigated the inhibitory effect of Gug on the growth of the human prostate cancer cells $[10,11]$. The results has shown that Gug significantly inhibits the proliferation of PC-3, LNCaP and DU145 human prostate cancer cells, but not a normal human prostate epithelial cell line PrEC [10,11]. The Gug-mediated suppression of cancer cell proliferation has also been reported in human breast cancer cells $[12,13]$, head and neck cancer cells [14], leukemia cells [15,16], lung cancer cells [16], skin cancer cells [17], and colon cancer cells [18]. Gug treatment inhibited angiogenesis in vitro and in vivo to block colon and prostate cancer growth $[18,19]$. Based on these data, we hypothesized that GL might be more effective in growth inhibition of prostate cancer cells because it contains a number of steroids, including the two isomers Z- and E-Gugs. Therefore, we investigated the anti-cancer potential of GL in human prostate cancer cells [20]. Our data, for the first time, showed that GL has a stronger anti-cancer potential in human prostate cancer cells as evidenced by inhibition of cell growth compared with Z-Gug, one of its active constituents. A statistically significant inhibition of cell survival by GL was evident at $\mathrm{IC}_{50} \sim 1 \mu \mathrm{mol} / \mathrm{L}$ concentrations standardized to $\mathrm{z}$-Gug. The effect on growth inhibition by GL was $\sim 10$-fold stronger than that of z-Gug [20]. Interestingly, a normal prostate epithelial cell line PrEC was significantly more resistant to growth inhibition by GL compared with prostate cancer cells [20]. Based on these results, we have arrived at the following conclusions: (a) GL treatment decreases the survival of human prostate cancer cells irrespective of their androgenresponsiveness, (b) a normal prostate epithelial cell line is significantly more resistant to growth inhibition by GL, and (c) uncharacterized constituent(s) of GL may interact additively or synergistically to inhibit viability of human prostate cancer cells [20]. It is reported that treatment with GL ( $3 \mu \mathrm{mol}$ standardized to $\mathrm{z}$-Gug, daily for 3 weeks) resulted in the enhancement of cetuximab activity in the xenograft model of head and neck cancer [21].

Although the mechanisms of the anti-cancer action of GL are not completely understood, these studies have indeed indicated that GL and its active components (Gugs) inhibit cancer cell viability by causing apoptosis $[10-14,16,17,20-25]$. The mechanisms underlying GL-induced apoptosis are involved in the change of Bcl-2 gene family proteins $[10,11,16,17,20]$, inhibition of NF-kB signaling [12,16,17,22], regulation of MAPK pathways [11,17,20], suppression of farnesoid X receptor [25] and the bile acid receptor [26], and the inhibition of EGFRSTAT3 signaling [14,21]. The results implicate the involvement of STAT3 and VEGF/VEGFR signaling pathways in the regulation of GLmediated anti-angiogenesis activity $[18,19]$. Tumor-specific induction of oxidative stress is expected to offer a powerful therapeutic modality. In fact, many anticancer agents and naturally occurring and synthetic agents exhibit antitumor activity via ROS-dependent activation of

${ }^{*}$ Corresponding author: Dong Xiao, MD. and Ph.D., Department of Urology University of Pittsburgh Cancer Institute, University of Pittsburgh School of Medicine, University of Pittsburgh, Shadyside Medical Center, Suit G19, 5200 Centre Avenue, Pittsburgh, PA 15232, USA, Tel: 412-623-3873; Fax 412-623-3907; E-mail: dongx@upmc.edu

Received November 14, 2012; Accepted November 15, 2012; Published November 16, 2012

Citation: Xiao M, Xiao D (2012) Gugulipid, an Extract of Ayurveda Medicine Plant Commiphora Mukul as a Potent Agent for Cancer Chemoprevention and Cancer Chemotherapy. Med chem (Los Angeles) 2:e105. doi:10.4172/2161-0444.1000e105

Copyright: (c) 2012 Xiao M, et al. This is an open-access article distributed under the terms of the Creative Commons Attribution License, which permits unrestricted use, distribution, and reproduction in any medium, provided the original author and source are credited. 
apoptotic cell death. Our results indicate that the cell death caused by GL in human prostate cancer cells is triggered by ROS generation [20]. This conclusion is based on: (a) GL treatment caused a dose- and timedependent ROS production in LNCaP and C81 cells; (b) GL-mediated ROS generation and apoptotic cell death were significantly attenuated by antioxidant NAC; and (c) the same treatment with GL did not affect the ROS induction and cause apoptotic cell death in PrEC. It was also reported by us $[10,11]$ that ROS is indispensable for $\mathrm{z}$-Gug, one of the important active components of GL, caused apoptosis in human prostate cancer PC-3 cells.

Even though pharmacokinetic parameters for GL have not been determined in humans, the maximal plasma concentration of $\mathrm{z}$-Gug $\left(C_{\max }\right)$ in rats was shown to be 3.3 - and $18.3 \mu \mathrm{mol} / \mathrm{L}$ following oral gavage with $50 \mathrm{mg} \mathrm{z}-\mathrm{Gug} / \mathrm{Kg}$ body weight and intravenous injection with $18 \mathrm{mg} \mathrm{z}$-Gug/Kg body weight [27]. Based on these pharmacokinetic observations, it is possible that the concentrations of GL $(1 \mu \mathrm{M})$ needed to inhibit cancer cell growth may be achievable in humans.

The studies reveal that GL is a potent inhibitor of cancer cell growth. GL is a multitargeted chemopreventive and chemotherapeutic agent. Future studies on GL should focus on: (a) the study of pharmacokinetics and bioavailability; (b) the in vivo study using xenogrfts, transgenic models and angiogenesis models as well as orthotropic models; and (c) the identification of biomarkers of GL response potentially useful in future clinical trials and in the optimization of GL-based regimens for prevention and therapy of cancer.

\section{Acknowledgments}

The research related to this article is partly supported by the National Institutes of Health National Cancer Institute Grant R21-CA143104 and the National Institutes of Health National Cancer Institute and Office of Dietary Supplements Grant RO1-CA157477 to DX.

\section{References}

1. Shishodia S, Harikumar KB, Dass S, Ramawat KG, Aggarwal BB (2008) The guggul for chronic disease: ancient medicine, modern targets. Anticancer Res 28: 3647-3664.

2. Urizar NL, liveman AB, Dodds DT, Silva FV, Ordentlich P, et al. (2002) A natural product that lowers cholesterol as an antagonist ligand for FXR. Science 296: 1703-1706.

3. Urizar NL, Moore DD (2003) GUGULIPID: a natural cholesterol-lowering agent. Annu Rev Nutr 23: 303-313.

4. Badmaev V, Majeed M, Pacchetti B, Prakash L (2003) Standardiation of Commiphora Mukul extract in dislipidemia and cardiovascular disease. NUTRA Foods 2: 45-51.

5. Gujral ML, Sareen K, Tangri KK, Amma MK, Roy AK (1960) Antiarthritic and anti-inflammatory activity of gum guggul (Balsamodendron mukul Hook). Indian J Physiol Pharmacol 4: 267-273.

6. Szapary PO, Wilfe ML, Bloedon LT, Cucchiara AJ, DerMarderosian AH, et al. (2003) Guggulipid for the treatment of hyperchlorlesterolemia: A randomized controlled trial. JAMA 290: 765-772.

7. Zhu N, Rafi MM, DiPaola RS, Xin J, Chin CK, et al. (2001) Bioactive constitutents from gum guggul (Commiphora wightii). Phytochemistry 56: 723-727.

8. Surh YJ (2003) Cancer chemoprevention with dietary phytochemicals. Nat Rev cancer 3: 768-780.

9. Sporn MB (1976) Approaches to prevention of epithelial cancer during the preneoplastic period. Cancer Res 36: 2699-2702.
10. Singh SV, Zeng Y, Xiao D, Vogel VG, Nelson JB, et al. (2005) Caspasedependent apoptosis induction by guggulsterone, a constituent of Ayurvedic medicinal plant Commiphora mukul, in PC-3 human prostate cancer cells is mediated by Bax and Bak. Mol Cancer Ther 4: 1747-1754.

11. Singh SV, Choi S, Zeng Y, Hahm ER, Xiao D (2007) Guggulsterone-induced apoptosis in human prostate cancer cells is caused by reactive oxygen intermediate-dependent activation of c-Jun $\mathrm{NH}_{2}$-terminal kinase. Cancer Res 67: 7439-7449.

12. Ichikawa H, Aggarwal BB (2006) Guggulsterone inhibits osteoclastogenesis induced by receptor activator of nuclear factor-kB ligand and by tumor cells by suppressing nuclear factor-KB activation. Clin Cancer Res 12: 662-668.

13. Krishnamurthy KK, Wang GH, Rokhfeld R, Bieberich E (2008) Deoxychlates promotes survival of breast cancer cells by reducing the level of pro-apoptotic ceramide. Breast Cancer Res 10: R106.

14. Leeman-Neill RJ, Wheeler SE, Singh SV, Thomas SM, Seethala RR, et al (2009) Guggulsterone enhances head and neck cancer therapies viainhibition of signal transducer and activator of transcription-3. Carcinegesis 11: 18481856.

15. Samudio I, Konopleva M, Safe S, McQueen T, Andreeff M (2005) Guggulsterone induce apoptosis and differentiation in acute myeloid leukemia: identification of isomer-specific antileukemic activities of the pregnadienedione structure. Mol Cancer Ther 4: 1982-1992.

16. Shishodia S, Aggarwal BB (2004) Guggulsterone inhibits NF-kappaB and IkappaBalpha kinase activation, suppresses expression of anti-apoptotic gene products, and enhances apoptosis. J Biol Chem 279: 47148-47158.

17. Sarfaraz S, Siddiqui IA, Syed DN, Afaq F, Mukhtar H (2008) Guggulsterone modulates MAPK and NF-kappaB pathways and inhibits skin tumorigenesis in SENCAR mice. Carcinogenesis 29: 2011-2018.

18. Kim ES, Hong SY, Lee HY, Kim SW, An MJ, et al. (2008) Guggulsterone inhibits angiogenesis by blocking STAT3 and VEGF expression in colon cancer cells. Oncol Rep 20: 1321-1327.

19. Xiao D, Singh SV (2008) z-Guggulsterone, a constituent of Indian Ayurvedic medicinal plant Commiphora mukul, inhibits angiogenesis in vitro and in vivo. Mol Cancer Ther 7: 171-180.

20. Xiao D, Zeng Y, Prakash L, Badmaev V, Majeed M, et al. (2011) Reactive oxygen species-dependent apoptosis by gugulipid extract of Ayuvedic medicine plant Commiphora mukul in human prostate cancer cells is regulated by c-JUN $\mathrm{N}$-terminal kinase. Mol Pharm 79: 499-507.

21. Leeman-Neill RJ, Seethala RR, Singh SV, Freilino ML, Bednash JS, et al. (2011) Inhibition of EGFR-STAT3 signaling with erlotinib prevents carcinogenesis in a chemically-induced mouse model of oral squamous cell carcinoma. Cancer Prev Res (Phila) 4: 230-237.

22. Niranjan R, Nath C, Shukla R (2011) Gugulipid and nimesulide differentially regulated inflammatory genes mRNA expressions via inhibition of NF-kB and CHOP activation inLPS-stimulated rat astrocytoma cells C6. Cell Mol Neurobiol 31: 755-764.

23. Xu HB, Li L, Liu GQ (2011) Reversal of multidrug resistance by guggulsterone in drug-resistant MCF-7 cell lines. Chemotherapy 57: 62-70.

24. Cheon JH, Kim JS, Kim JM, Kim N, Jung HC, et al. (2006) Plant stero guggulsterone inhibits nuclear factor-kappaB signaling in intestinal epithelial cells by blocking IkappaB kinase and ameliorates acute murine colitis. Inflamm Bowel Dis 12: 1152-1161.

25. Cui J, Huang L, Zhao A, Lew JL, Yu J, et al. (2003) Guggulsterone is a farnesoid $X$ receptor antagonist in coactivator association assays but acts to enhance transcription of bile salt export pump. J Biol Chem 278: 10214-10220.

26. Wu J, Xia C, Meier J, Li S, Hu X, et al. (2002) The hypolipidemic natural product guggulsterone acts as an antagonist of the bile acid receptor. Mol Endocrinol 16: $1590-1597$.

27. Verma N, Singh SK, Gupta RC (1999) Pharmacokinetics of guggulsterone after intravenous and oral administration in rats. Pharm Pharmacol Comm 5: 349354. 